\title{
Mechanistic Approaches to the Light-Induced Neural Cell Differentiation: Photobiomodulation vs Low-Dose Photodynamic Therapy
}

Nermin Topaloglu ( $\nabla$ nermint@gmail.com )

Izmir Katip Celebi University: Izmir Katip Celebi Universitesi https://orcid.org/0000-0001-7001-8327 Emel Bakay

Izmir Katip Celebi University: Izmir Katip Celebi Universitesi

\section{Research Article}

Keywords: photobiomodulation, photodynamic therapy, intracellular reactive oxygen species, nitric oxide release, neural differentiation, $\mathrm{PC} 12$ cells

Posted Date: October 5th, 2021

DOI: https://doi.org/10.21203/rs.3.rs-953775/v1

License: (c) (i) This work is licensed under a Creative Commons Attribution 4.0 International License.

Read Full License

Version of Record: A version of this preprint was published at Photodiagnosis and Photodynamic Therapy on December 1st, 2021. See the published version at https://doi.org/10.1016/j.pdpdt.2021.102702. 


\section{Abstract}

Neurodegenerative diseases are the results of irreversible damages in the neuronal cells by affecting vital functions temporarily or even permanently. The use of light for the treatment of these diseases is an emerging promising innovative method. Photobiomodulation (PBM) and Photodynamic Therapy (PDT) are the modalities that have a wide range of use in medicine and have opposite purposes, biostimulation and cell death respectively. In this study, we aimed to compare these two modalities (PDT and PBM) at low-level intensities and create a stimulatory effect on the differentiation of PC12 cells. Three different energy densities $(1,3$, and $5 \mathrm{~J} / \mathrm{cm} 2)$ were used in PBM and Chlorin e6-mediated PDT applications upon irradiation with 655-nm laser light. The light-induced differentiation profile of PC12 cells was analyzed by morphological examinations, qRT-PCR, cell viability assay, and some mechanistic approaches such as; the analysis of intracellular ROS production, NO release, and mitochondrial membrane potential change. It has been observed that both of these modalities were successful at neural cell differentiation. PBM at 1 $\mathrm{J} / \mathrm{cm} 2$ and low-dose PDT at $3 \mathrm{~J} / \mathrm{cm} 2$ energy densities provided the best differentiation profiles which were proved by the over-expressions of SYN-1 and GAP43 genes. It was also observed that intracellular ROS production and NO release had pivotal roles in these mechanisms with more cell differentiation obtained especially in low-dose PDT application. It can be concluded that light-induced mechanisms with properly optimized light parameters have the capacity for neural cell regeneration and thus, can be a successful treatment for incurable neurodegenerative diseases.

\section{Introduction}

The treatment of neurodegenerative diseases such as Parkinson's, Alzheimer's, and dementia is still controversial and even not possible. Many people in the world are struggling with these types of diseases [1]. Patients are affected irreversibly due to the inability of neural cells to divide, reproduce, and regenerate [2]. From past to present, light has been used to treat different diseases. The use of light applications in the visible and near-infrared spectrum also for neural diseases is a promising and valuable candidate for therapeutic purposes [3]. Yang and colleagues reported that the application of near-infrared light on neuroprogenitor cells increased cortical neurogenesis and synaptogenesis by improving the neuronal microenvironment [4]. In another study, it was shown that red light applied to nerve cells increases neuron elongation and stimulates neural maturation [5]. There are also several in vivo studies that reported the effects of various wavelengths through the mechanism of PBM with great improvements on the function of the different brain structures [6,7]. These findings increase the hope that light can stimulate neuronal cells to reproduce and regenerate as a treatment tool for diseases that result from neuronal cell loss.

Photobiomodulation (PBM) works by applying low-level visible or near-infrared light to the target tissue or the cells without any adverse effect [8] and triggers different biochemical reactions by stimulating several signaling pathways in the cell metabolism $[9,10]$. As a result of these reactions, some cellular and tissue level effects such as DNA synthesis, ATP production, cell proliferation, wound healing, neurogenesis, increase in blood flow, and decrease in pain, inflammation, or oxidative stress may occur depending on the type of target tissue and the cell $[9,11]$. Although there are many assumptions about the cellular 
mechanism of action of PBM, there is a commonly accepted finding that the biochemical reactions start with the absorption of light by the enzyme of cytochrome $c$ oxidase, which is a mitochondrial electron transport chain element, then intracellular reactive oxygen species (ROS) are produced, the mitochondrial membrane potential (MMP) increases and it results in a protein gradient across the cell and mitochondrial membrane. Beside the production of intracellular ROS, there is a release of nitric oxide (NO) and ATP production in the cells that are treated by light at low-level intensities [12, 13]. ATP synthesis, intracellular ROS production, and NO release show their effects in the long-term follow-up of the cell behaviors $[14,15]$. Thereby, it is understood that the primary effect of light applications on the cells via photobiomodulation is the change in mitochondrial membrane potential after the absorption of light energy by cytochrome c oxidase. This was first suggested by Karu and Passarella in their studies that explained the increase in mitochondrial membrane potential and proton gradient, then in turn increase in ATP production and oxygen consumption after NIR light application $[16,17]$. Wong-Riley proved that NIR light applications, especially at the wavelengths of 670 and 830-nm, increased the activity of cytochrome c oxidase and by this way increased the activity of energy metabolism in primary neuronal cells which were treated by cytochrome c oxidase inhibitor [18]. The strongly accepted assumption about the mechanism of light absorption by cytochrome $\mathrm{c}$ oxidase and the increase in the activity of this enzyme via light is related to the NO blockade between the copper and heme centers of cytochrome c oxidase. It was hypothesized that absorbed light by this enzyme breaks the non-covalent bonds between the NOs and these centers, then this mechanism results in increased activity of cytochrome c oxidase and NO release. Thus, NO release is another important indicator of photobiomodulation therapy $[17,19]$. However, it is also assumed that the cells in injured tissues or hypoxic conditions have a higher amount of NO release than healthy cells have upon irradiation [17].

Another therapeutic method in which light is commonly used as a tool is photodynamic therapy (PDT). The main idea of PDT is to destroy cancer and some non-malignant cells with the help of light-sensitive chemicals (photosensitizers), which can absorb strongly a certain wavelength and start a cascade of energy transfer reactions resulting in ROS production [20,21]. The amount of ROS produced after light absorption by the photosensitizer determines the degree of phototoxicity on the cells. As a golden rule in PDT, photosensitizer and light do not cause a detrimental effect on the target separately. When they are applied together, the generation of the high amount of ROS is achieved as toxic compounds and they kill the target cells. Their toxic behaviors depend on the amount of the quantum oxygen yield of the photosensitizers upon irradiation. It was also stated by Topaloglu and colleagues that a low concentration of ROS may induce biostimulation and a high concentration of ROS causes photodynamic action, which results in cell death [22]. This fact was also the starting point for PBM. It was first accidentally found in an experiment that studied the low-level laser application on the rodent tumor cells with the wrong laser intensities, which were quite low and not efficient to induce anti-tumor activity and ultimately accelerated the wound healing process [23]. Since that day, the mechanism of PBM was studied intensionally to clarify any cellular processes that happen after light absorption by the endogenous chromophores in the cells. However, there are still unclear issues that need to be explained in PBM. The mechanism of PDT is much more clear and its action mostly depends on the administration of 
the exogenous chromophores which are the photosensitizers and sometimes can be triggered via endogenous protoporphyrin IX (PPIX) by using the precursor of 5-Aminolevulinic acid (5-ALA) [24, 25].

There are several types of photosensitizers, which absorb the wavelengths in the visible and near-infrared region [26]. Mono-L-aspartyl chlorin e6 (Ce6) is a frequently used photosensitizer against both pathogens and cancer cells in PDT studies [27, 28]. It is preferred due to its high stability, feasibility, effectiveness [27], and its quite high quantum oxygen yield [29]. Thus, its detrimental effect through the photodynamic action is due to its high quantum yield upon irradiation and it strongly absorbs the wavelengths around 650-nm [28] that extremely comply with the absorption band of cytochrome c oxidase [17].

It is known that PBM and PDT share a common basis depending mainly on the biphasic dose-response of the cells against the light [17, 30-32]. PBM or PDT may induce inhibitory or excitatory effects on cellular mechanisms through the changes in mitochondrial membrane potential, intracellular ROS level, and NO release, which are the commonly observed instances for both of these mechanisms [17, 23, 33]. In this study, we aimed to show that PBM and PDT applications with fundamentally opposite purposes, which are biostimulation and cell killing respectively, can be used for the same purpose that is to induce neural cell differentiation. Thus, we examined the biostimulative effect of PBM with a red light on the neural differentiation of PC12 cell line using different energy doses at first, then the same protocol was repeated via low-dose PDT applied with the same energy densities used in PBM applications in the presence of a very low concentration Ce6 to induce cell differentiation on the same neural cell model. The differentiation rates of PC12 cells after PBM and low-dose PDT applications were compared morphologically in terms of neurite length, the number of neurites per cell, and the percentage of the differentiated cells. Then, the role of produced intracellular ROS, changes in the mitochondrial membrane potential, and the NO release were analyzed by specific mechanistic approaches in both PBM and lowdose PDT applications. Furthermore, the outcomes of those analyses were supported by the quantitative real-time polymerase chain reaction (qRT-PCR) analysis with the expression of specific two genes (SYN-1 and GAP43) in both applications.

\section{Materials And Methods}

\section{Materials}

Collagen (type IV, 0.5-2 mg/ml), RPMI-1640, nerve growth factor (NGF, Vipera lebetina venom), trypsinEDTA, L-glutamine, 3-(4,5-dimethythiazol-2-yl)-2,5-diphenyl tetrazolium bromide (MTT), Phosphate buffered saline tablets (PBS), and 2',7'-dichlorofluorescin diacetate (DCFH-DA) were supplied from SigmaAldrich (St. Louis, MO, USA). Gentamicin and fetal bovine serum (FBS) were purchased from Gibco (Dublin, Ireland). Donor horse serum (DHS) was purchased from Capricorn (Ebsdorfergrund, Germany). Dimethyl Sulfoxide (DMSO) solution was purchased from Merck (Darmstadt, Germany). Chlorin e6 (Ce6) was purchased from Santa Cruz (Texas, USA). Griess reagent kit was purchased from Biotium (Fremont, CA, USA), JC1-Mitochondrial Membrane Potential assay kit was purchased from Abcam (Cambridge, UK). 
Blood/Cell Total RNA Mini Kit was purchased from Geneaid (Sijhih City, Taiwan). M-MuLV First Strand cDNA Synthesis Kit was purchased from Biomatik (Ontario, Canada).

\section{Cell Line and Culture Condition}

Depending on the neural properties they have, pheochromocytoma cells (PC12) were used as a model to mimic neural cells [34], which were purchased from DSMZ (Braunschweig, Germany). They were grown in RPMI- 1640 containing 10\% DHS, 1\% FBS, 1\% L-glutamine, and $0.1 \%$ gentamicin in an atmosphere humidified with $5 \% \mathrm{CO}_{2}$ at $37^{\circ} \mathrm{C}$. After they reached $80 \%$ confluency, $5 \times 10^{3}$ cells for differentiation and cell viability analysis and $1 \times 10^{6}$ cells for the other mechanistic analysis were seeded into each well of the 96-well plates that were collagen-coated to provide the cell attachment and cultured in the growth medium for $24 \mathrm{~h}$ in an atmosphere humidified with $5 \% \mathrm{CO}_{2}$ at $37^{\circ} \mathrm{C}$ for the applications.

\section{Light Source}

A diode-pumped laser device with a wavelength of $655 \mathrm{~nm}$ was used as the light source (PS4 III. LED; Changchun New Industries Optoelectronics Tech. Ltd., China). The output power of the laser device was adjusted to $50 \mathrm{~mW}$. For the calculations of the application times and energy densities, the formula of;

Energy Density $\left(\mathrm{J} / \mathrm{cm}^{2}\right)=$ Output Power $(\mathrm{W}) /$ Area $\left(\mathrm{cm}^{2}\right) \times$ Time $(\mathrm{s})$

was used. The laser light that came out of the optical fiber of the laser device illuminated perpendicularly an area of approximately $12.56 \mathrm{~cm}^{2}(\mathrm{r}=2 \mathrm{~cm})$ which covered 4 wells of a 96-well plate. The output power and the illuminated area were kept constant and the energy densities were adjusted to 1,3 , and $5 \mathrm{~J} / \mathrm{cm}^{2}$ by changing the application time. All the applied parameters in PBM and Low-PDT applications were given in Table 1 below.

\section{$<$ Table 1.>}


Ce6 is a second-generation chlorine class photosensitizer used in PDT applications with a molecular formula of $\mathrm{C}_{34} \mathrm{H}_{36} \mathrm{~N}_{4} \mathrm{O}_{6}$ and a molecular weight of $596.684 \mathrm{~g} / \mathrm{mol}$. In this study, it was used to induce low-dose PDT. The first stock solution of Ce6 was prepared in serum-free RPMI-1640 medium by dissolving it with the help of an ultrasonic water bath for several minutes. This stock solution was diluted with the serum-containing medium to prepare a secondary stock solution and it was vortexed vigorously to prevent any aggregation. Then six different concentrations of Ce6 $(0.1,0.25,0.5,1.0,2.5$, and $5 \mu \mathrm{M})$ were prepared via diluting the secondary stock solution with the serum-containing medium. Drug preparation and all other applications with Ce6 were performed in the dark to prevent photobleaching.

These six concentrations of Ce6 were applied on PC-12 cells to observe whether the photosensitizer alone had any toxic effect on the cells and to determine the optimum concentration for low-dose PDT applications. The Ce6 solutions were added onto the cells and incubated for $1 \mathrm{~h}$ at $37^{\circ} \mathrm{C}$ in an atmosphere humidified with $5 \% \mathrm{CO}_{2}$. After the cells were washed with PBS at the end of the incubation, MTT analysis was performed at the $1^{\text {st }}, 24^{\text {th }}$, and $48^{\text {th }}$ hours to observe the long term toxicity of the photosensitizer by absorbance measurement with a microplate reader (Multimode Microplate Reader Biotek Synergy HTX, Biotek, Winooski, VT, USA). Depending on the results of the cytotoxicity analysis, a nontoxic concentration was chosen to be used in low-dose PDT applications.

\section{Experimental Protocols for PBM and Low-Dose PDT}

The following groups were formed for PBM and low-dose PDT applications:

- Control group: Without any light or photosensitizer application formed separately for PBM and PDT groups,

$-1 \mathrm{~J} / \mathrm{cm}^{2}$ Group: $1 \mathrm{~J} / \mathrm{cm}^{2}$ of energy density applied alone for PBM applications and in the presence of Ce6 for PDT applications,

- $3 \mathrm{~J} / \mathrm{cm}^{2}$ Group: $3 \mathrm{~J} / \mathrm{cm}^{2}$ of energy density applied alone for PBM applications and in the presence of Ce6 for PDT applications,

- $5 \mathrm{~J} / \mathrm{cm}^{2}$ Group: $5 \mathrm{~J} / \mathrm{cm}^{2}$ of energy density applied alone for PBM applications and in the presence of Ce6 for PDT applications.

In PBM applications, the growth medium was removed from the cells before the application and a fresh growth medium containing $50 \mathrm{ng} / \mathrm{ml}$ NGF was added to the cells. Then, the cells were incubated for $1 \mathrm{~h}$ in 
the presence of NGF at $37^{\circ} \mathrm{C}$ before light applications. In PDT applications, the growth medium was removed, Ce6 solution was added and incubated with the cells for $1 \mathrm{~h}$ at $37^{\circ} \mathrm{C}$. Then, the Ce6 solution was removed, the cells were washed with PBS to remove all the residues of the photosensitizer. The fresh growth medium containing $50 \mathrm{ng} / \mathrm{ml}$ NGF was added to the cells. Finally, the cells were incubated for $1 \mathrm{~h}$ in the presence of NGF at $37^{\circ} \mathrm{C}$ before light applications. Throughout the experiments, triple light treatment was performed both in PBM and low-dose PDT groups with a 24-hour interval. In low-dose PDT groups, Ce6 incubation was repeated with each light application. The timetable below shows the flow of the applications from cell seeding to the end of the experiments (Figure 1).

<Fig. 1. >

\section{Analysis of the PC12 Cell Differentiation, Neurite Formation, and Elongation}

The differentiation capacity of PC-12 cells in all groups was investigated morphologically in terms of neurite length, the number of neurites per cell, and the percentage of the differentiated cells on days 1,2 , 3,4 , and 7. The microscopic images of the living cells were captured with a 20X magnification using an inverted microscope (Olympus, CKX41, Tokyo, Japan). 10 images were examined from each sample. The total neurite length, the number of neurites per cell, and the percentages of the differentiated cell in each group were calculated using the Image J program ( $\mathrm{NIH}$, Bethesda, MD, USA).

\section{Cell Viability Analysis}

MTT assay was used to determine cell viability percentages at the end of the 7-day follow-up. MTT reagent was first prepared in distilled water as a $5 \mathrm{mg} / \mathrm{ml}$ stock solution and then it was diluted to be $10 \%$ in each well. The cells were incubated with MTT solution for $2 \mathrm{~h}$. At the end of the incubation, the MTT solution was removed, the cells were washed once with PBS, and then incubated with DMSO for 30 minutes. Finally, the absorbance values were measured at $570 \mathrm{~nm}$ of wavelength by the microplate reader. These measured absorbance values in each group were used to calculate the cell viability percentages of the cells by normalizing them with the data of the control group.

Intracellular ROS Measurement 
The amount of intracellular ROS generated as a result of laser applications was determined by 2',7'dichlorofluorescin diacetate (DCFH-DA). DCFH-DA is a non-fluorescent compound that can be converted into dichlorofluorescein (DCF), which is a fluorescent compound in the presence of ROS. Before the applications, the cells were incubated with $0.1 \mathrm{mM}$ of DCFH-DA solution for 45 minutes and they were washed with PBS twice to remove all the DCFH-DA that did not enter the cells. Afterward, the specific applications were performed to each sample whether they were in PBM or low-dose PDT groups. When the applications have finished, the fluorescence intensity of DCF was measured immediately with an excitation wavelength of $485 / 20 \mathrm{~nm}$ and an emission wavelength of 528/20 nm using the microplate reader.

\section{Analysis of NO Release}

The amount of NO released as a result of laser applications was determined using Griess reagent containing sulfanilic acid and $\mathrm{N}$-(1-naphthyl)ethylenediamine. Nitrite molecules, which are the breakdown product of NO, react with sulfanilic acid and N-(1-naphthyl)ethylenediamine to form a dye molecule that can be determined spectrophotometrically. 1 hour and 24 hours after the applications were completed, the same volume of Griess reagent and the supernatant solution from each sample were mixed and incubated for 30 minutes at room temperature. The absorbance values of each sample were measured at $548 \mathrm{~nm}$ of wavelength with the microplate reader. Besides, a standard curve (concentration vs absorbance) was formed with the standard nitrite solution. The formula of this standard curve $(y=$ $0.0014 x+0.0404, R^{2}=0.999$ ) was used to calculate the amount of nitrite in each sample as an indication of NO released after the applications and these data were normalized with its corresponding control group.

\section{Measurement of Mitochondrial Membrane Potential}

The mitochondrial membrane potential change during the light applications was determined by the JC1Mitochondrial Membrane Potential assay kit according to the manufacturer's instructions. Before the light applications, the cells were washed with the dilution buffer and then incubated with $10 \mathrm{mM}$ of $\mathrm{JC}-1$ solution for 10 minutes at $37^{\circ} \mathrm{C}$. After the incubation, the cells were washed with the dilution buffer twice and the specific application protocols were performed in each PBM and PDT group. The fluorescent signals were read immediately at an excitation wavelength of $475 \mathrm{~nm}$ and the emission wavelengths of $530 \mathrm{~nm}$ for a red fluorescence and $590 \mathrm{~nm}$ for a green fluorescence with the microplate reader. After 
measuring absorbance values for the mitochondrial membrane potential change, the images of the experimental groups were taken with a fluorescent microscope (Olympus CKX41, Olympus Co. Ltd., Tokyo, Japan). These images were obtained with CellSens Imaging Software, and the red fluorescence represented the hyperpolarization of cells, and the green fluorescence represented the depolarization of the cells in the images.

\section{Quantitative Real-Time PCR Analysis for the Expressions of GAP43 and SYN-1 genes}

When the 7-day of cell differentiation follow-up was completed in each group, the total RNA was obtained by the Blood/Cell Total RNA Mini Kit. Then, the M-MuLV First Strand cDNA Synthesis Kit was used to convert the obtained RNA into CDNA, which was then used in the qRT-PCR process with the primer sets of Glyceraldehyde-3-Phosphate Dehydrogenase (GAPDH), Growth Associated Protein 43 (GAP43), and synapsin 1 (SYN-1) genes (Atlas Biotechnology, Turkey) by using StepOne Plus Real-Time PCR System (Applied Biosystems, Foster City, USA). GAPDH gene was used as a housekeeping gene with the forward and reverse sequences of 5'-TGGCGCTGAGTACGTCGTG-3' and 5'-ATGGCATGGACTGTGGTCAT-3', respectively. The forward and the reverse sequences of the GAP43 gene were 5'AGAAAGCAGCCAAGCTGAGGAGG-3' and 5'-CAGGAGAGACAGGGTTCAGGTGG-3', respectively. The forward and the reverse sequences of the synapsin 1 gene were 5'-CAGGGTCAAGGCCGCCAGTC-3' and 5'CACATCCTGGCTGGGTTTCTG-3'. At least three gene expression analysis was performed for each sample and the expressions of the genes were evaluated according to the expression of the GAPDH gene using StepOne Software v2.3.

\section{Statistical Analysis}

All the applications were repeated three times and there were three samples in each group. GraphPad Prism Version 9.0.1 (GraphPad Software Inc., La Jolla, CA, USA) was used for the statistical comparison of the experimental groups. The data obtained in each analysis, whether they were normalized with respect to the control group or the data itself, were analyzed with a one-way analysis of variance (ANOVA) at first. Then, Tukey's post hoc test was used to make statistical comparisons between the data of the experimental and the control groups. A $p$-value smaller than $5 \%$ was considered statistically significant.

\section{Results And Discussion}

\section{Ce6 did not induce any cytotoxicity on PC-12 Cells}


Various concentrations $(0.1,0.25,0.5,1,2.5$, and $5 \mu \mathrm{M})$ of Ce6 were administered to PC1 2 cells to analyze the dark toxicity of the photosensitizer. They were quite lower concentrations than that of commonly used concentrations in photodynamic therapy applications, which aims for cell killing [28]. The main purpose of this analysis was to determine the safe concentrations and not to induce any detrimental effects on the cells when applied in low-dose PDT. The data of the cell metabolic activities obtained from MTT analysis showed in Fig. 2 that none of these 6 concentrations exhibited a cytotoxic effect on PC1 2 cells. The metabolic activity was screened for 48 hours. Instead of a decrease in cell viability, remarkable increases were observed generally after the administration of Ce6. It was assumed that these low concentrations of Ce6 might induce cellular stress on cells which in turn resulted in the stimulation of cell survival mechanisms and then ended up with cell proliferation [17]. Nevertheless, the smallest concentration was chosen for low-dose PDT applications.

<Fig. 2. $>$

\section{PC12 Cell Viability after PBM and Low-Dose PDT Applications}

The metabolic activity of the cells after the triple light treatment via PBM or low-dose PDT applications at different energy densities $\left(1,3\right.$, and $\left.5 \mathrm{~J} / \mathrm{cm}^{2}\right)$ was analyzed with MTT assay. As shown in Fig. 3, any of these treatments did not induce significant decreases or increases in cell viability. The most remarkable decrease, which was a nearly $25 \%$ decrease in cell viability, was observed in the PDT group at $1 \mathrm{~J} / \mathrm{cm}^{2}$ energy density. Surprisingly, PBM applications at 3 and $5 \mathrm{~J} / \mathrm{cm}^{2}$ energy densities resulted in a similar decrease as in the PDT group at $1 \mathrm{~J} / \mathrm{cm}^{2}$. However, they were not significantly different from the control group. There were slight increases in the cell viability of the PBM and PDT groups at 1 and $3 \mathrm{~J} / \mathrm{cm}^{2}$ energy densities, respectively. These were the groups in which more differentiated cells were observed throughout this study.

<Fig. 3. $>$

PBM and Low-Dose PDT induced PC12 Cell Differentiation, Neurite Formation, and Neurite Elongation 
PC-12 cells were treated with PBM and low-dose PDT applications at three different energy densities and then their differentiation potentials were examined morphologically on days $1,2,3,4$, and 7 . The microscopic images of the PC12 cells in PBM groups obtained at days 1, 2, 3, 4, and 7 are shown in Fig. 4 and the microscopic images of the PC12 cells in low-dose PDT groups obtained at days 1, 2, 3, 4, and 7 are shown in Fig. 5.

\section{<Fig. 4. >}

<Fig. 5. $>$

These microscopic images were evaluated in terms of average neurite length, percentage of the differentiated cells, and the frequency of the neurite numbers per cell (Fig. 6. and Fig. 7) PBM application at $1 \mathrm{~J} / \mathrm{cm}^{2}$ energy density induced longer neurite formation throughout the 7-day evaluation period. The average neurite length achieved in this group was nearly $270 \mathrm{~mm}$ and it was significantly different from the control that resulted in $175 \mathrm{~mm}$ of neurite length at the end of the $7^{\text {th }}$ day. Besides, it was significantly different from the groups of 3 and $5 \mathrm{~J} / \mathrm{cm}^{2}$. PBM applications at 3 and $5 \mathrm{~J} / \mathrm{cm}^{2}$ energy densities were also successful in terms of neurite length with an average of 234 and $236 \mathrm{~mm}$, respectively. The outcomes of these energy densities were also significantly different from the control group (Fig. 6. A.).

\section{<Fig. 6. >}

In low-dose PDT groups, $3 \mathrm{~J} / \mathrm{cm}^{2}$ energy density was more successful for the formation of longer neurites than the other energy densities. In this application, nearly $131 \mathrm{~mm}$ neurite length was achieved on average and it was significantly different from the control that resulted in $103 \mathrm{~mm}$ neurite length. The neurite lengths achieved in 1 and $5 \mathrm{~J} / \mathrm{cm}^{2}$ low-dose PDT applications, which was 112 and $122 \mathrm{~mm}$ respectively, were also longer than the neurite length obtained in the control group at the end of the $7^{\text {th }}$ day, but only $5 \mathrm{~J} / \mathrm{cm}^{2}$ energy density resulted in a statistically different outcome than the control group. It was also observed that PBM induced longer neurites than the low-PDT applications did (Fig. 7. A.).

<Fig. 7. > 
PC12 cells were also evaluated whether they formed neurite(s) or not and it was considered as differentiation when they formed neurite(s). Depending on their neurite formation capacity, the number of differentiated cells was calculated as a percentage. All the energy densities used in PBM applications induced significantly higher percentages of differentiation with respect to the control group throughout the 7-day follow-up. Again $1 \mathrm{~J} / \mathrm{cm}^{2}$ energy density in PBM was the most effective light dose on the differentiation ability of PC12 cells (Fig. 6. B.). Similarly, all the energy densities in low-dose PDT applications resulted in more differentiated cells than that of the control group. The most successful energy density for this modality was $3 \mathrm{~J} / \mathrm{cm}^{2}$, which ended up with more than $86 \%$, differentiated cells and it was also higher than the outcome of PBM application at $1 \mathrm{~J} / \mathrm{cm}^{2}$ energy density (Fig. 7. B.).

When the neurite forming capacity of the cells was examined in terms of the frequency of the neurite numbers per cell, neurite formations started at the $2^{\text {nd }}$ day in all low-dose PDT and PBM groups. The cells in PBM groups formed single, double, and triple neurites per cell immediately on the $2^{\text {nd }}$ day. The formation of four neurites per cell started on the $3^{\text {rd }}$ day and the formation of five neurites per cell started on the $4^{\text {th }}$ day during the 7-day follow-up. The incidence of single neurite formation was quite high. Then they continued the neurite formation as extra neurites on each cell, therefore the frequency of the single neurites decreased while the frequency of the more than single neurites increased. Each energy density used in PBM applications induced similar behavior of neurite formation (Fig. 6. C.). For low-dose PDT applications, not only the formation of single, double, and triple neurites was observed on the $2^{\text {nd }}$ day, but also the formation of four and five neurites on a single cell was observed immediately after the $1^{\text {st }}$ light application. Thus, the frequency of each number of neurites was generally lower in low-dose PDT groups when compared with the frequency of neurite numbers in PBM groups. After each light application, the frequency of single or double neurites decreased. However, the frequency of triple, four, and five neurites increased day by day (Fig. 7. C.). In general, low-dose PDT and PBM groups were found to have higher neurite forming capacity at all energy doses compared to the control group.

\section{Low-Dose PDT Application resulted in more Intracellular ROS Production compared to PBM Applications}

Intracellular ROS production after the applications was analyzed by the non-fluorescent probe of DCFHDA, which is converted into fluorescent DCF in the presence of ROS. For PBM and low-dose PDT applications, triple light treatments were performed at a 24-hour interval. It is known that these modalities are responsible for the intracellular ROS production after the light absorption with a specific chromophore in the target, whether the application is PBM or PDT [17]. Thus, intracellular ROS analysis was repeated immediately to follow up the changes in ROS levels in the cells after each light application. As it was shown in Fig. 8, the highest increase in ROS level in the cells was observed after the second light application of low-dose PDT at $3 \mathrm{~J} / \mathrm{cm}^{2}$ energy density with a nearly $50 \%$ change with respect to the control group. For PBM applications, the highest increase in ROS level was observed after the third light 
application at $1 \mathrm{~J} / \mathrm{cm}^{2}$ energy density with a nearly $10 \%$ change with respect to the control group. Besides these, only slight changes in ROS levels were observed (Fig. 8.)

<Fig 8. >

This was an expected result that PDT, in general, has more capacity than PBM has, to induce more intracellular ROS production via light absorption by an exogenous chromophore. This is the way that PDT destroys cancer cells or pathogens [24]. By keeping the level of light energy and photosensitizer concentration low, we assumed that we can eliminate the detrimental effect of PDT via low-level intracellular ROS production, but still stimulate the production of more intracellular ROS than PBM does at the same energy densities. When we looked at the average neurite length and percentage of the differentiated cells, there were remarkable increases in both of these analyses after the low-dose PDT application at $3 \mathrm{~J} / \mathrm{cm}^{2}$ energy density which also provided the highest level of intracellular ROS. These results verified our assumption that intracellular ROS was a stimulant agent for the differentiation of the cells after low-dose PDT. Similarly, longer neurite lengths and more differentiated cells were obtained after PBM applications at $1 \mathrm{~J} / \mathrm{cm}^{2}$ energy density which provided more ROS production than the other PBM groups did.

\section{Significant NO Release was observed after PBM and Low-Dose PDT Applications at specific energy densities}

Upon light irradiation, cytochrome c oxidase absorbs the light energy and it will result in the release of NO that is non-covalently bonded to the copper and heme centers of this enzyme. Thus, NO is a wellaccepted indicator of photobiomodulation [17]. The released NO can be detected by Griess reagent via nitrite molecules (the breakdown product of NO) reacting with sulfanilic acid and $\mathrm{N}-(1-$ naphthyl)ethylenediamine and forming a dye molecule which can be analyzed spectrophotometrically. In this study, NO release was investigated in both low-dose PDT and PBM groups via nitrite molecules. As it was mentioned above, NO release depends on light absorption. So, their analyses were repeated for each light application during the triple light treatment process. Fig. 9. A. showed the values of NO release $1 \mathrm{~h}$ after the light applications, Fig. 9. B. showed the values of $\mathrm{NO}$ release $24 \mathrm{~h}$ after the light applications. As it was represented in Fig. 9. A., PBM application at $1 \mathrm{~J} / \mathrm{cm}^{2}$ energy density resulted in significantly different increases after $1^{\text {st }}$ and $3^{\text {rd }}$ light treatments $1 \mathrm{~h}$ after the applications. Especially the $3^{\text {rd }}$ light application of PBM at $1 \mathrm{~J} / \mathrm{cm}^{2}$ energy density induced a drastic increase which was more than $350 \%$, in the nitrite level compared to the control group. Other energy densities in PBM and all the energy densities 
of low-dose PDT applications did not induce significant changes in the level of NO release $1 \mathrm{~h}$ after the applications. When we examined the nitrite levels 24 hours after the applications, more changes were observed in almost all experimental groups compared to the control group (Fig. 9. B.). Especially $1 \mathrm{~J} / \mathrm{cm}^{2}$ energy density in PBM and $3 \mathrm{~J} / \mathrm{cm}^{2}$ energy density in PDT applications resulted in significantly different increases in the nitrite level after the $1^{\text {st }}$ and $2^{\text {nd }}$ light treatments as shown in Fig. 9. B. These increases were not so drastic, but approximately $40 \%$ increases were obtained with these applications. In general, we can say that the process of NO release from the mitochondria continued in a period of 24 hours. The most distinct changes in this analysis were again obtained after the $3^{\text {rd }}$ light application of PBM at 1 $\mathrm{J} / \mathrm{cm}^{2}$ energy density when it was measured 1 hour after the applications and after the $2^{\text {nd }}$ light application of low-dose PDT at $3 \mathrm{~J} / \mathrm{cm}^{2}$ energy density when it was measured 24 hours after the applications. Not surprisingly, these are the same applications that were responsible for the longer neurite elongation, more cell differentiation, and a high level of intracellular ROS production.

Actually, we expected more significant differences in each experimental group because of the important role of NO in the mechanism of photobiomodulation [35]. In some cases, we observed decreases in the level of nitrite molecules which were not statistically significant (Fig. 9). In photobiomodulation, it is known that light irradiation stimulates a cascade of biochemical reactions that end up with superoxides which then react with released NO molecules to form peroxynitrite [36]. The enzyme of superoxide dismutase (MnSOD), which is in the matrix of the mitochondria, has a specific role to decrease oxidative stress by dismutating superoxides into hydrogen peroxide and molecular oxygen. This enzyme competes with the released NO and prevents the interaction between superoxide and NO [37]. In this study, we have used an indirect method with Griess reagent to detect the breakdown products of the released NO, which are nitrite molecules. We assumed that the activity of MnSOD might diminish the prevalence of those molecules and prevent the detection of them, which might be the cause of the decreases in nitrite levels of some experimental groups (Fig. 9). Besides, it is also known that more NO release is expected in pathological conditions, such as wounds or tumor environments. These conditions are hypoxic and under hypoxic conditions, cytochrome $\mathrm{c}$ oxidase activates the signaling mechanism via NO. Thus, more NO release can be observed in these conditions. Normally, the enzymatic activity of cytochrome c oxidase can proceed via $\mathrm{H}_{2} \mathrm{O}$ or NO. The oxygen concentration in the environment determines which pathway will be used by cytochrome c oxidase. Under normal oxygen concentration, cytochrome c oxidase works by $\mathrm{H}_{2} \mathrm{O}$ causing ROS release. However, a low level of oxygen concentration causes cytochrome c oxidase to use the other pathway via NO that results in more NO release [38]. In our study, the environment of the cells was not hypoxic. This might be the other reason why we did not detect more nitrite molecules or in some cases, we detected some decreases in the nitrite levels after the light applications given the idea that the enzymatic activity of cytochrome c oxidase was activated via $\mathrm{H}_{2} \mathrm{O}$.

<Fig. 9. > 


\section{Mitochondrial Membrane Potential Change was more pronounced in Low-Dose PDT Application than that of PBM Application}

It is known that light absorption by cytochrome c oxidase causes the separation and release of NO. Its place is then occupied by oxygen and the electrons are transported along the respiratory chain. This creates a proton gradient across the mitochondrial membrane, which then results in changes in MMP, ATP level, and intracellular ROS production [39]. In our study, MMP changes were examined by the JC-1 probe after each light application. When the MMP is higher than -140 mV (hyperpolarization), the JC-1 probe forms J-aggregates in the mitochondria and their fluorescence emission can be detected at 590$\mathrm{nm}$. When MMP is lower than $-100 \mathrm{mV}$ (depolarization), J-monomers are formed and detected as green fluorescence at 530-nm [40]. PBM and PBM-like mechanisms induce hyperpolarization of the mitochondria and generally, depolarization expresses cell death [41, 42]. As shown in Fig. 10. A., the intensity of the red fluorescence in each application is quite high compared to the control group, which implied an increase in MMP of the light-induced cells. It was also observed that low-dose PDT was more effective inducing hyperpolarization of the cells. Especially, the $1^{\text {st }}$ light treatment at $3 \mathrm{~J} / \mathrm{cm}^{2}$ provided a $20 \%$ increase in low-dose PDT application, which was the highest change in MMP obtained in this study. Similar changes were also obtained after the $3^{\text {rd }}$ light application of low-dose PDT at 3 and $5 \mathrm{~J} / \mathrm{cm}^{2}$ energy densities. The most remarkable change in MMP after PBM applications was only obtained after the $1^{\text {st }}$ light application at $1 \mathrm{~J} / \mathrm{cm}^{2}$ (Fig. 10. B.). Again we observed that the same energy densities either in PBM or low-dose PDT, which were responsible for the remarkable changes in the previous analysis, induced the hyperpolarization of the PC12 cells.

<Fig. 10. >

\section{PBM and Low-Dose PDT Applications Overexpressed GAP43 and SYN-1 genes}

Synapsin 1 and GAP 43 are important proteins for neuronal cells and are expressed by SYN-1 and GAP 43 genes, respectively. Synapsin 1 protein has an important role in synaptogenesis and the release of neurotransmitters [43]. As shown in Fig. 11. A., light applications, either PBM or low-dose PDT, predominantly increased the expression of the SYN-1 gene and almost provided three times higher expression than that of the control group. Low-dose PDT application at $3 \mathrm{~J} / \mathrm{cm}^{2}$ resulted in the highest 
expression of synapsin 1 protein. The least effective application was low-dose PDT at $5 \mathrm{~J} / \mathrm{cm}^{2}$. However, it was still higher than the control group (Fig. 11. A.).

GAP43 protein is called growth-associated protein 43 and is responsible for neurite formation, regeneration, and plasticity [44]. This protein is overexpressed during brain development, then its expression decreases after maturation. As it is shown in Fig. 11. B., it was overexpressed after light applications whether it was PBM or low-dose PDT, similar to the expression profile of synapsin 1. Lowdose PDT application at $3 \mathrm{~J} / \mathrm{cm}^{2}$ energy density provided the highest expression of GAP 43 , which was almost 8 times the expression in the control group. Besides, PBM applications at 1 and $3 \mathrm{~J} / \mathrm{cm}^{2}$ energy densities were also very effective to induce the expression of this gene. Only, $5 \mathrm{~J} / \mathrm{cm}^{2}$ group of low-dose PDT resulted in a decrease in the expression of GAP43 with respect to the control group (Fig. 11. B.).

<Fig. 11. >

The results of the gene expression analysis for SYN-1 and GAP 43 after the PBM and low-dose PDT applications supported the findings of neurite formation and elongation analysis, measurement of intracellular ROS, NO release, and MMP change. In general, $3 \mathrm{~J} / \mathrm{cm}^{2}$ energy density in PDT groups provided the highest gene expression for both of the gene types and for PBM applications, 1 and $3 \mathrm{~J} / \mathrm{cm}^{2}$ energy densities overexpressed these genes. Both of these modalities were successful for the induction of PC12 cell differentiation and low-dose PDT application provided better outcomes, which were also supported by the results of the qRT-PCR analysis. It was assumed that a higher level of intracellular ROS produced in low-dose PDT was the main molecule that initiated several signaling mechanisms and resulted in overexpression of SYN-1 and GAP43 genes to achieve desired differentiation of the cells.

Several studies showed the success of PBM on neuronal cells in vitro and in vivo $[12,45]$. Thus, it is offered as a promising modality for neurodegenerative diseases and traumatic brain injuries, because of its capability to induce neural cell differentiation and regeneration. Especially the wavelengths in red and near-infrared ranges provided successful treatments $[12,46]$. Saito et al. used a diode laser at a wavelength of 810-nm and analyzed PC12 cell differentiation at two different energy densities (5 and 20 $\mathrm{J} / \mathrm{cm}^{2}$ ). They showed that near-infrared light application induced PC12 cell differentiation [34]. In another study, Yang et al. showed that PBM with $808 \mathrm{~nm}$ of wavelength supported neurogenesis and differentiation after brain stroke in rats [4]. Duan et al. examined the effect of PBM via LED irradiation at a wavelength of $640-\mathrm{nm}$ and found that PBM prevented apoptosis of PC12 cells treated with amyloid bpeptide [47]. According to the mechanistic analysis in previous PBM applications, it was approved that ROS were formed after light absorption and provided many beneficial outcomes such as accelerated wound healing and a decrease in inflammation [7, 48, 49]. Similarly, we understood that intracellular ROS production should be the key mechanism for the stimulation of PC12 cell differentiation in PBM and low- 
dose PDT applications. When Giuliani et al. examined the effect of $670-\mathrm{nm}$ laser irradiation on PC12 cells under oxidative stress, PBM induced neurite elongation, increased the cell viability even under oxidative stress and protected the neural cells by recovering their mitochondrial membrane potentials [5]. In our study, PBM applications at 655 -nm of wavelength showed similar positive effects on PC12 cells as expected. Three different energy densities were examined and as mentioned previously [34], lower doses were more successful at neural cell differentiation. Beside the important role of intracellular ROS in these mechanisms, it should also be added that NO release is the other important factor that induces photobiomodulation-related phenomena. Light application at $1 \mathrm{~J} / \mathrm{cm}^{2}$ in PBM caused an immediate and drastic increase in nitrite levels. As it is commonly known that the photon energy is absorbed directly by cytochrome c oxidase in PBM and this influences the release of NO molecules that are bound to mitochondria $[17,19]$. This might be the reason for such a drastic increase at this energy density which was responsible for the most biostimulative effect in PBM groups of this study. When we consider the effect of PDT, it is not so directly related to the mitochondria, as in the case of PBM. The chromophore molecule was not mitochondria, in this case, the photon energy was absorbed by the photosensitizer which was Ce6. Thus the effect of this application on mitochondria and NO release from mitochondria was not so immediate and drastic. The increases in NO levels were observed $24 \mathrm{~h}$ after the PDT applications. Nevertheless, the same energy densities in each application, whether it was PBM or lowdose PDT, were responsible for the intracellular ROS production, NO release, or neural differentiation at the end. Thus, these outcomes strengthen the assumption that intracellular ROS production and NO release were the key factors for PBM or low-dose PDT-mediated neural differentiation.

Previously, low-dose PDT applications were used for the same stimulatory effect on different cell lines, such as keratinocytes [44] and osteoblasts [50,51]. Blazques-Castro and colleagues found that protoporphyrin IX mediated PDT increased the proliferation of keratinocytes via increase intracellular ROS [52]. Ates and colleagues examined the effect of two different photosensitizers (methylene blue and indocyanine green) on osteoblast differentiation via PDT applications and stated that this modality contributed to osteoblast cell differentiation by increasing the alkaline phosphatase activity [50,51]. Not only these in vitro studies but also some in vivo studies that examined the positive effects of low-dose PDT on animal models gave us the hope to carry out this study. Silva et al. used phthalocyanine-based photosensitizer together with $685-\mathrm{nm}$ of wavelength to treat the wounds on Wistar rats. The wounds were irradiated at an energy density of $2.5 \mathrm{~J} / \mathrm{cm}^{2}$ following the photosensitizer administration. At the end of this application, they ended up with enhanced wound healing [53]. In a similar study, infected abrasion wounds were treated with the indocyanine green-mediated PDT and as a result, infection was eliminated and the wound healing process was accelerated noticeably [54]. Zhang and the colleagues specifically examined the effect of low-dose PDT with photofrin and a diode laser that emitted a wavelength of 632$\mathrm{nm}$ on the brain of nude mice. They observed that there was a significant increase in the proliferation of endothelial cells and the vascular endothelial growth factor (VEGF) expression. The authors declared that these results were obtained in a dose-dependent manner [55]. The maximum expressions of SYN-1 and GAP43 genes were obtained in low-dose PDT application in this study. Similar to the study of Zhang et al., the level of the gene expressions obtained via low-dose PDT depended on the energy density applied 
and $3 \mathrm{~J} / \mathrm{cm}^{2}$ energy density was the most effective dose. Thus, these results revealed the importance of the light dosimetry that determines the degree of the stimulatory effect whether it is PBM or low-dose PDT [56]. The optimization and the proper selection of the light parameters are of great importance to achieve the desired biostimulative effect on cells or tissues.

\section{Conclusions}

The treatment of neurodegenerative diseases or traumatic brain injuries is impossible because of the dysfunctional neural cells that cannot regenerate themselves. Photobiomodulation is a very promising therapy that may induce the differentiation and the regeneration of neural cells. In this study, PC12 cells were used as a model cell line for the neural cells and two different modalities (PBM and low-dose PDT) were used to induce the differentiation of the PC12 cells. Morphological examinations, mechanistic approaches, and qRT-PCR analysis showed that both of these modalities were successful in neural cell differentiation and low-dose PDT application provided even more promising outcomes compared to PBM by properly optimizing the energy density and the photosensitizer concentration. It was observed that lowdose PDT application can hasten the underlying mechanisms of cellular differentiation and provide more accurate, reliable, and rapid therapy using the biphasic dose characteristic of light applications for tissue response via intracellular ROS production and NO release.

\section{References}

[1] Reddy, A.P., Ravichandran, J., \& Carkaci-Salli, N. (2020). Neural regeneration therapies for Alzheimer's and Parkinson's disease-related disorders. Biochimica et Biophysica Acta-Molecular Basis of Disease, 1866(4):165506.

[2] Silver, J., Schwab, M.E., \& Popovich, P. G. (2015). Central nervous system regenerative failure: role of oligodendrocytes, astrocytes, and microglia. Cold Spring Harbor Perspectives in Biology, 7(3):a020602.

[3] Coulter, A.H. (2003). Let there be light-and healing. Alternative and Complementary Therapies, 9(6):322-326.

[4] Yang, L., Tucker, D., Dong, Y., Wu, C., Lu, Y., Li, Y., Zhang, J., Liu, T. C. Y., \& Zhang, Q. (2018). Photobiomodulation therapy promotes neurogenesis by improving post-stroke local microenvironment and stimulating neuroprogenitor cells. Experimental Neurology, 299:86-96.

[5] Giuliani, A., Lorenzini, L., Gallamini, M., Massella, A., Giardino, L., \& Calzà, L. (2009). Low infra-red laser light irradiation on cultured neural cells: effects on mitochondria and cell viability after oxidative stress. BMC Complementary and Alternative Medicine, 9(1):8.

[6] Lu, Y., Wang, R., Dong, Y., Tucker, D., Zhao, N., Ahmed, M. E., Zhu, L., Liu, T. C. Y., Cohen, R.M., \& Zhang, Q. (2017). Low-level laser therapy for beta amyloid toxicity in rat hippocampus. Neurobiology of Aging, 49:165-182. 
[7] Bathini, M., Raghushaker, C.R., \& Mahato, K. K. (2020). The Molecular Mechanisms of Action of Photobiomodulation Against Neurodegenerative Diseases: A Systematic Review. Cellular and Molecular Neurobiology, 1-17.

[8] Hawkins, D. \& Abrahamse, H. (2006). Effect of multiple exposures of low-level laser therapy on the cellular responses of wounded human skin fibroblasts. Photomedicine and Laser Surgery, 24(6):705-714.

[9] Hennessy, M. \& Hamblin, M. R. (2016). Photobiomodulation and the brain: a new paradigm. Journal of Optics, 19(1):013003.

[10] Topaloglu, N., Özdemir, M., \& Yaralı Çevik, Z. B. (2021). Comparative analysis of the light parameters of red and near-infrared diode lasers to induce photobiomodulation on fibroblasts and keratinocytes: An in vitro study. Photodermatology, Photoimmunology \& Photomedicine, 37(3):253-262.

[11] de Freitas, L. F. \& Hamblin, M. R. (2016). Proposed mechanisms of photobiomodulation or low-level light therapy. IEEE Journal of Selected Topics in Quantum Electronics, 22(3):348-364.

[12] Salehpour, F., Mahmoudi, J., Kamari, F., Sadigh-Eteghad, S., Rasta, S. H., \& Hamblin, M. R. (2018). Brain photobiomodulation therapy: a narrative review. Molecular Neurobiology, 55(8):6601-6636.

[13] Mamalis, A., Siegel, D., \& Jagdeo, J. (2016). Visible red light emitting diode photobiomodulation for skin fibrosis: key molecular pathways. Current Dermatology Reports, 5(2):121-128.

[14] Mignon, C., Botchkareva, N. V., Uzunbajakava, N. E., \& Tobin, D. J. (2016). Photobiomodulation devices for hair regrowth and wound healing: a therapy full of promise but a literature full of confusion. Experimental Dermatology, 25(10):745-749.

[15] Hamblin, M. R. (2008). The role of nitric oxide in low level light therapy. In: Biomedical Optics (BiOS), International Society for Optics and Photonics, San Jose, California, USA, 684602.

[16] Karu, T. (1999). Primary and secondary mechanisms of action of visible to near-IR radiation on cells. Journal of Photochemistry and Photobiology B: Biology, 49(1):1-17.

[17] Hamblin, M. R. (2018). Mechanisms and mitochondrial redox signaling in photobiomodulation. Photochemistry and Photobiology, 94(2):199-212.

[18] Wong-Riley, M. T. T, Liang, H. L., Eells, J. T., Chance, B., Henry, M. M., Buchmann, E., Kane, M., \& Whelan, H. T. (2005). Photobiomodulation directly benefits primary neurons functionally inactivated by toxins: role of cytochrome c oxidase. Journal of Biological Chemistry, 280(6):4761-4771.

[19] Lane, N. (2006). Power games. Nature, 443:901-903.

[20] Topaloğlu, N., Kadıköylü, G., Onak, G., \& Karaman, O. (2020). The effect of indocyanine green-based photodynamic therapy on healthy fibroblast and keratinocyte cells. Photodiagnosis and Photodynamic 
Therapy, 31:101891.

[21] Vatansever, F., de Melo, W. C. M. A., Avci, P., Vecchio, D., Sadasivam, M., Gupta, A., Chandran, R., Karimi, M., Parizotto, N. A., Yin, R., Tegos, G. P., \& Hamblin, M. R. (2013). Antimicrobial strategies centered around reactive oxygen species-bactericidal antibiotics, photodynamic therapy, and beyond. FEMS Microbiology Reviews, 37(6):955-989.

[22] Topaloglu, N., Guney M., Aysan, N., Gulsoy, M., \& Yuksel, S. (2016). The role of reactive oxygen species in the antibacterial photodynamic treatment: photoinactivation vs proliferation. Letters in Applied Microbiology, 62(3):230-236.

[23] Mester, E., Spiry, T., Szende, B., \& Tota, J. G. (1971). Effect of laser rays on wound healing. The American Journal of Surgery, 122(4):532-535.

[24] Foo, A. S. C., Soong, T.W., Yeo, T. T., \& Lim, K. L. (2020). Mitochondrial Dysfunction and Parkinson's Disease-Near-Infrared Photobiomodulation as a Potential Therapeutic Strategy. Frontiers in Aging Neuroscience, 12:89.

[25] Kloek, J. \& Beijersbergen van, H. (1996). Prodrugs of 5-aminolevulinic acid for photodynamic therapy. Photochemistry and Photobiology, 64:994-1000.

[26] Topaloglu, N., Gulsoy, M., \& Yuksel, S. (2013). Antimicrobial photodynamic therapy of resistant bacterial strains by indocyanine green and 809-nm diode laser. Photomedicine and Laser Surgery, $31(4): 155-162$.

[27] Bharathiraja, S., Moorthy, M. S., Manivasagan, P, Seo, H., Lee, K. D., \& Oh, J. (2017). Chlorin e6 conjugated silica nanoparticles for targeted and effective photodynamic therapy. Photodiagnosis and Photodynamic Therapy, 19:212-220.

[28] Avşar, N. T., Bakay, E., \& Kolkıran, A. (2020). Photodynamic action of chlorin e6 against methicillin resistant staphylococcus aureus with the aid of ethanol. Archives of Clinical and Experimental Medicine, 5(3):100-105.

[29] Fernandez, J. M., Bilgin, M. D., \& Grossweiner, L. I. (1997). Singlet oxygen generation by photodynamic agents. Journal of Photochemistry and Photobiology B: Biology, 37(1-2):131-140.

[30] Tanaka, M., Kinoshita, M., Yoshihara, Y., Shinomiya, N., Seki, S., Nemoto, K., Hamblin, M.R., \& Morimoto, Y. (2011). Photodynamic therapy using intra-articular photofrin for murine MRSA arthritis: Biphasic light dose response for neutrophil-mediated antibacterial effect. Lasers in Surgery and Medicine, 43:221-229.

[31] Kazantzis, K. T., Mavroidi, K. K.

B., Zachariadis, M., Alexiou, P., Pelecanou, M., Politopoulos, K., Alexandratou E., \& Sagnou 
M. (2020). Curcumin derivatives as photosensitizers in photodynamic therapy: photophysical properties and in vitro studies with prostate cancer cells. Photochemical and Photobiological Sciences, 19:193-26.

[32] Tanaka, M., Kinoshita, M., Yoshihara, Y., Shinomiya, N., Seki, S., Nemoto, K., Hirayama, T., Dai, T., Huang, L., Hamblin, M.R., \& Morimoto, Y. (2012). Optimal Photosensitizers for Photodynamic Therapy of Infections Should Kill Bacteria but Spare Neutrophils. Photochemistry and Photobiology, 88:227-232.

[33] Ball, K. A., Castello, P. R., \& Poyton, R. O. (2011). Low intensity light stimulates nitrite-dependent nitric oxide synthesis but not oxygen consumption by cytochrome $c$ oxidase: Implications for phototherapy. Journal of Photochemistry and Photobiology B: Biology, 102(3):182-191.

[34] Saito, K., Hashimoto, S., Jung, H. S., Shimono, M., \& Nakagawa, K. I. (2011). Effect of diode laser on proliferation and differentiation of pc12 cells. The Bulletin of Tokyo Dental College, 52(2):95-102.

[35] Huang, Y. Y., Sharma, S. K., \& Hamblin, M. R. (2011). Biphasic dose response in low level light therapy -an update. Dose-Response, 9:602-618.

[36] Lubart, R., Eichler, M., Lavi, R., Friedman, H., \& Shainberg, A. (2005). Low-energy laser irradiation promotes cellular redox activity. Photomedicine and Laser Surgery, 23(1):3-9.

[37] Chavez, M. D., Lakshmanan N, Kavdia M. (2007). Impact of superoxide dismutase on nitric oxide and peroxynitrite levels in the microcirculation-a computational model. In $29^{\text {th }}$ Annual International Conference of the IEEE Engineering in Medicine and Biology Society, Lyon, France, 1022-1026.

[38] Poyton, R. O. \& Ball, K. A. (2011). Therapeutic photobiomodulation: nitric oxide and a novel function of mitochondrial cytochrome c oxidase. Discovery Medicine, 11(57):154-159.

[39] Hamblin, M. R. (2016). Shining light on the head: photobiomodulation for brain disorders. $B B A$ Clinical, 6:113-124.

[40] Yang, Y., Zong, Y., Sun, Q., Jia, Y., \& Zhao, R. (2017). White light emitting diode suppresses proliferation and induces apoptosis in hippocampal neuron cells through mitochondrial cytochrome $\mathrm{C}$ oxydase-mediated IGF-1 and TNF-a pathways. Free Radical Biology and Medicine 113:413-423.

[41] Zupin, L., Barbi, E., Sagredini, R., Ottaviani, G., Crovella, S., \& Celsi, F. (2021). In vitro effects of photobiomodulation therapy on 50B11 sensory neurons: evaluation of cell metabolism, oxidative stress, mitochondrial membrane potential (MMP), and capsaicin-induced calcium flow. Journal of Biophotonics, 14:e202000347.

[42] Chen, Z., Li, W., Hu, X., \& Liu, M. (2020). Irradiance plays a significant role in photobiomodulation of B16F10 melanoma cells by increasing reactive oxygen species and inhibiting mitochondrial function. Biomedical Optics Express, 11(1):27-39. 
[43] Waterhouse, E. G. \& Xu, B. (2009). New insights into the role of brain-derived neurotrophic factor in synaptic plasticity. Molecular and Cellular Neuroscience, 42(2):81-89.

[44] Rosskothen-Kuhl, N. \& Illing, R. B. (2014). Gap43 Transcription Modulation in the Adult Brain Depends on Sensory Activity and Synaptic Cooperation. PloS one, 9(3):e92624.

[45] Quirk, B. J., Torbey, M., Buchmann, E., Verma, S., \& Whelan, H. T. (2012). Near-infrared photobiomodulation in an animal model of traumatic brain injury: improvements at the behavioral and biochemical levels. Photomedicine and Laser Surgery, 30(9):523-529.

[46] de Andrade, A. L. M., Bossini, P. S., do Canto De Souza, A. L. M., Sanchez, A. D., \& Parizotto, N. A. (2017). Effect of photobiomodulation therapy $(808 \mathrm{~nm})$ in the control of neuropathic pain in mice. Lasers in Medical Science, 32(4):865-872.

[47] Duan, R., Zhu, L., Liu, T. C. Y., Li, Y., Liu, J., Jiao, J., Xu, X., Yao, L., \& Liu, S. (2003). Light emitting diode irradiation protect against the amyloid beta $25-35$ induced apoptosis of PC12 cell in vitro. Lasers in Surgery and Medicine, 33(3):199-203.

[48] Amaroli, A., Ravera, S., Baldini, F., Benedicenti, S., Panfoli, I., and Vergani, L. (2019).

Photobiomodulation with 808-nm diode laser light promotes wound healing of human endothelial cells through increased reactive oxygen species production stimulating mitochondrial oxidative phosphorylation. Lasers in Medical Science, 34(3):495-504.

[49] Suzukawa, K., Miura, K., Mitsushita, J., Resau, J., Hirose, K., Crystal, R., \& Kamata, T. (2000). Nerve growth factor-induced neuronal differentiation requires generation of Rac1-regulated reactive oxygen species. Journal of Biological Chemistry, 275(18):13175-13178.

[50] Ateş, G. B., Ak, A., Garipcan, B., \& Gülsoy, M. (2017). Methylene blue mediated photobiomodulation on human osteoblast cells. Lasers in Medical Science, 32(8):1847-1855.

[51] Ateş, G. B., Ak, A., Garipcan, B., \& Gülsoy, M. (2018). Indocyanine green-mediated photobiomodulation on human osteoblast cells. Lasers in Medical Science, 33(7):1591-1599.

[52] Blázquez-Castro, A., Carrasco, E., Calvo, M. I., Jaén, P., Stockert, J. C., Juarranz, Á., Sanz-Rodriguez, F., \& Espada, J. (2012). Protoporphyrin IX-dependent photodynamic production of endogenous ROS stimulates cell proliferation. European Journal of Cell Biology, 91(3):216-223.

[53] Silva, J. C. E., Lacava, Z. G. M., Kuckelhaus, S., Silva, L. P., Neto, L. F. M., Sauro, E.E., \& Tedesco, E. A. C. (2004). Evaluation of the use of low level laser and photosensitizer drugs in healing. Lasers in Surgery and Medicine, 34(5):451-457.

[54] Topaloglu, N., Güney, M., Yüksel, S., \& Gülsoy, M. (2015). Antibacterial photodynamic therapy with 808-nm laser and indocyanine green on abrasion wound models. Journal of Biomedical Optics, 20(2):028003. 
[55] Zhang, X., Jiang, F., Zhang, Z. G., Kalkanis, S. N., Hong, X., deCarvalho, A. C., Chen, J., Yang, H., Robin, A. M., \& Chopp, M. (2005). Low-dose photodynamic therapy increases endothelial cell proliferation and VEGF expression in nude mice brain. Lasers in Medical Science, 20(2):74-79.

[56] Zein, R., Selting, W., \& Hamblin, M. R. (2018). Review of light parameters and photobiomodulation efficacy: dive into complexity. Journal of Biomedical Optics, 3(12):120901.

\section{Declarations}

\section{Funding}

This research did not receive any specific grant from funding agencies in the public, commercial, or notfor-profit sectors.

\section{Conflict of Interest Statement}

The authors have stated explicitly that there are no conflicts of interest in connection with this article.

\section{Availability of data and material}

The data that support the findings of this study are available from the corresponding author upon reasonable request.

\section{Code availability}

Not applicable

\section{Authors' contributions}

All authors contributed to the study conception and design. Material preparation, data collection, and analysis were performed by Nermin Topaloglu and Emel Bakay. The first draft of the manuscript was written by Nermin Topaloglu and all authors commented on previous versions of the manuscript. All authors read and approved the final manuscript.

\section{Ethics approval}


This article does not contain any study with human participants or animals performed by any of the authors.

\section{Consent to participate}

Not applicable

\section{Consent for publication}

All authors agreed with the content and all gave explicit consent to submit the manuscript for publication.

\section{Acknowledgments}

The authors thank Assoc. Prof. Mustafa Şen for providing PC12 cell line, Assoc. Prof. Utku Kürşat Ercan for providing JC-1 Mitochondrial Membrane Potential Assay Kit, Assist. Prof. Didem Şen Karaman for providing Griess Reagent, and Ziyşan Buse Yaralı Çevik for their valuable contributions during the qRTPCR analysis.

\section{Tables}

Table 1. The parameters of the light and photosensitizer used in PBM and low-dose PDT applications.

\begin{tabular}{|c|c|c|c|c|}
\hline & $\begin{array}{c}\mathrm{Ce} 6 \\
{[\mathrm{mM}]}\end{array}$ & $\begin{array}{c}\text { Output } \\
\text { Power } \\
{[\mathrm{mW}]}\end{array}$ & $\begin{array}{l}\text { Energy Density [J } \\
\left.\qquad \mathrm{cm}^{-2}\right]\end{array}$ & $\begin{array}{c}\text { Exposure Duration } \\
\text { [seconds] }\end{array}$ \\
\hline \multirow[t]{3}{*}{ PBM } & \multirow[t]{3}{*}{0} & \multirow[t]{3}{*}{50} & 1 & 251 \\
\hline & & & 3 & 754 \\
\hline & & & 5 & 1256 \\
\hline \multirow{3}{*}{$\begin{array}{c}\text { Low-Dose } \\
\text { PDT }\end{array}$} & \multirow[t]{3}{*}{0.1} & \multirow[t]{3}{*}{50} & 1 & 251 \\
\hline & & & 3 & 754 \\
\hline & & & 5 & 1256 \\
\hline
\end{tabular}




\section{Figures}

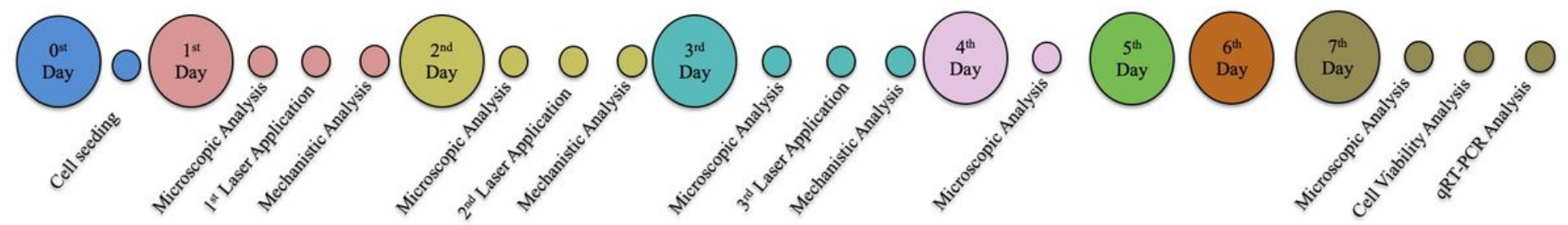

\section{Figure 1}

The timeline shows all the steps and applications carried out within their specific time intervals throughout the whole flow of experimentations

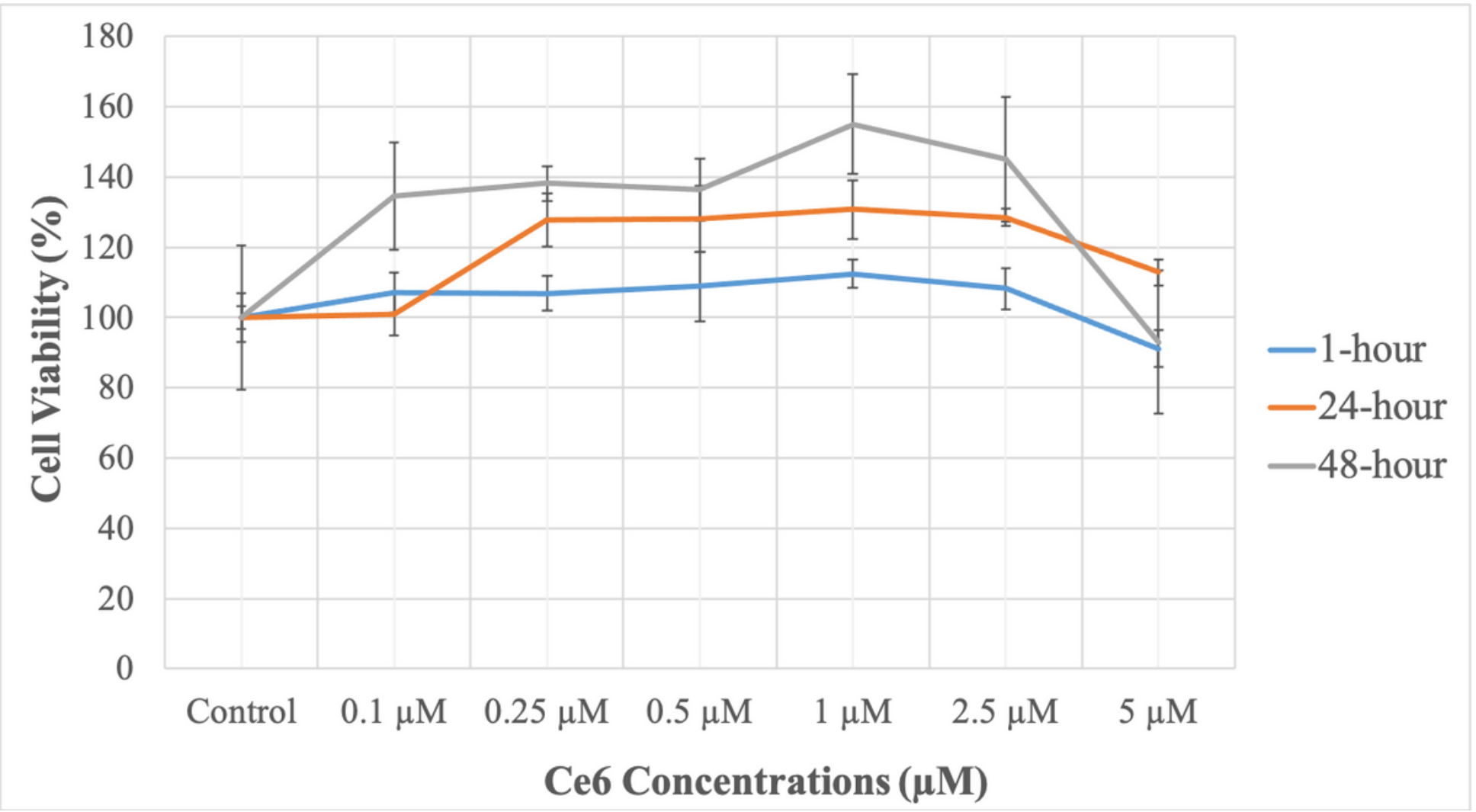

Figure 2

Ce6 Cytotoxicity on PC12 cells. The cells were treated with 6 different Ce6 concentrations $(0.1,0.25,0.5$, $1,2.5$, and $5 \mu \mathrm{M}$ ) and their metabolic activity was analyzed by MTT assay after 1,24 , and 48 hours. Each bar represented the average of the normalized data with respect to control group \pm Standard deviation (SD) 


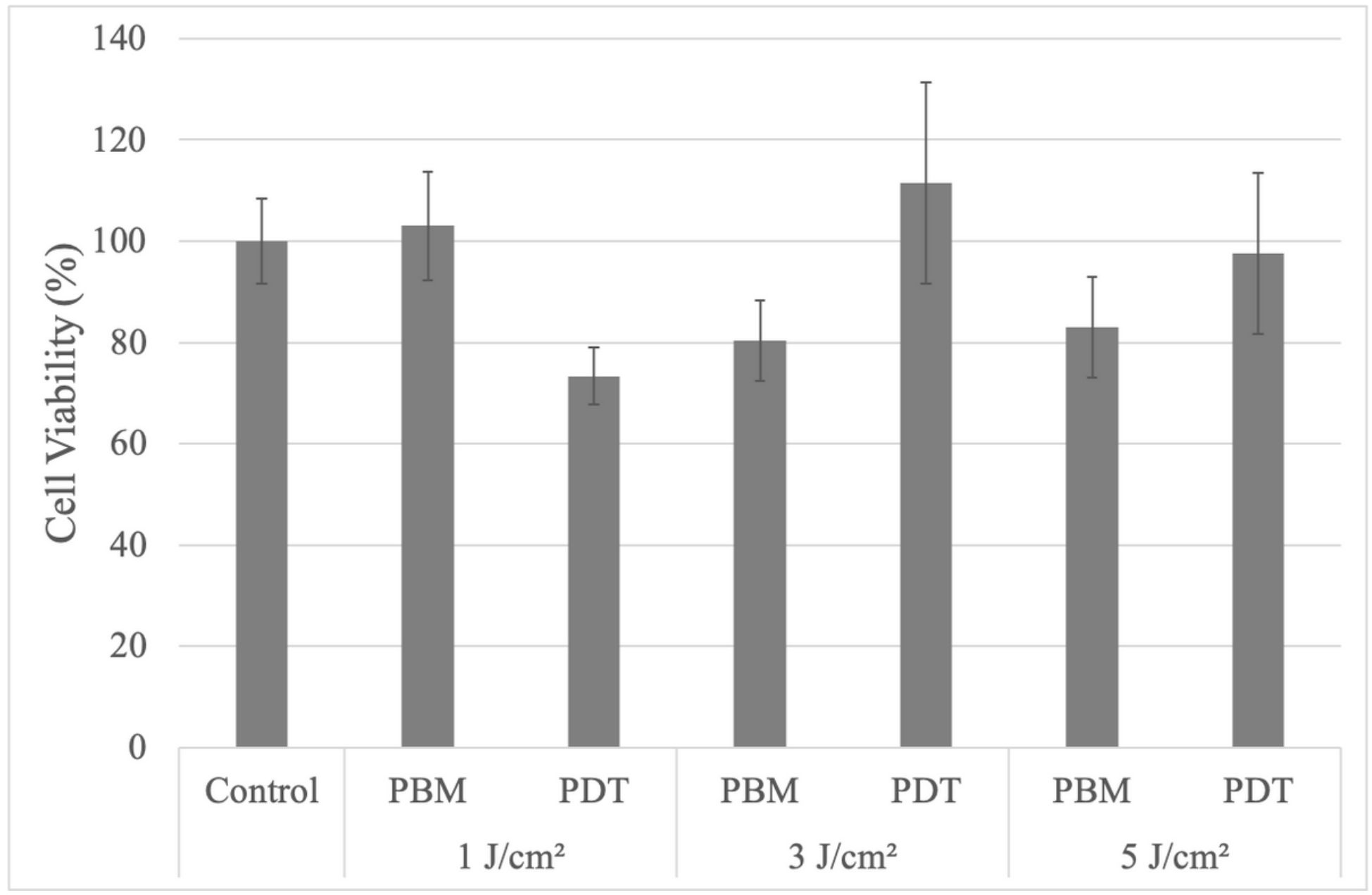

Figure 3

Cell Viability Analysis after PBM and low-dose PDT applications. The metabolic activity of the cells was analyzed by MTT assay upon irradiation in each experimental group. Each bar represented the average of the normalized data with respect to the control group \pm SD. For PBM applications the applied energy densities: 1,3 , and $5 \mathrm{~J} / \mathrm{cm} 2$ and for low-dose PDT applications the applied energy densities: 1,3 , and 5 $\mathrm{J} / \mathrm{cm} 2$ and Ce6 concentration: $0.1 \mu \mathrm{M}$ 


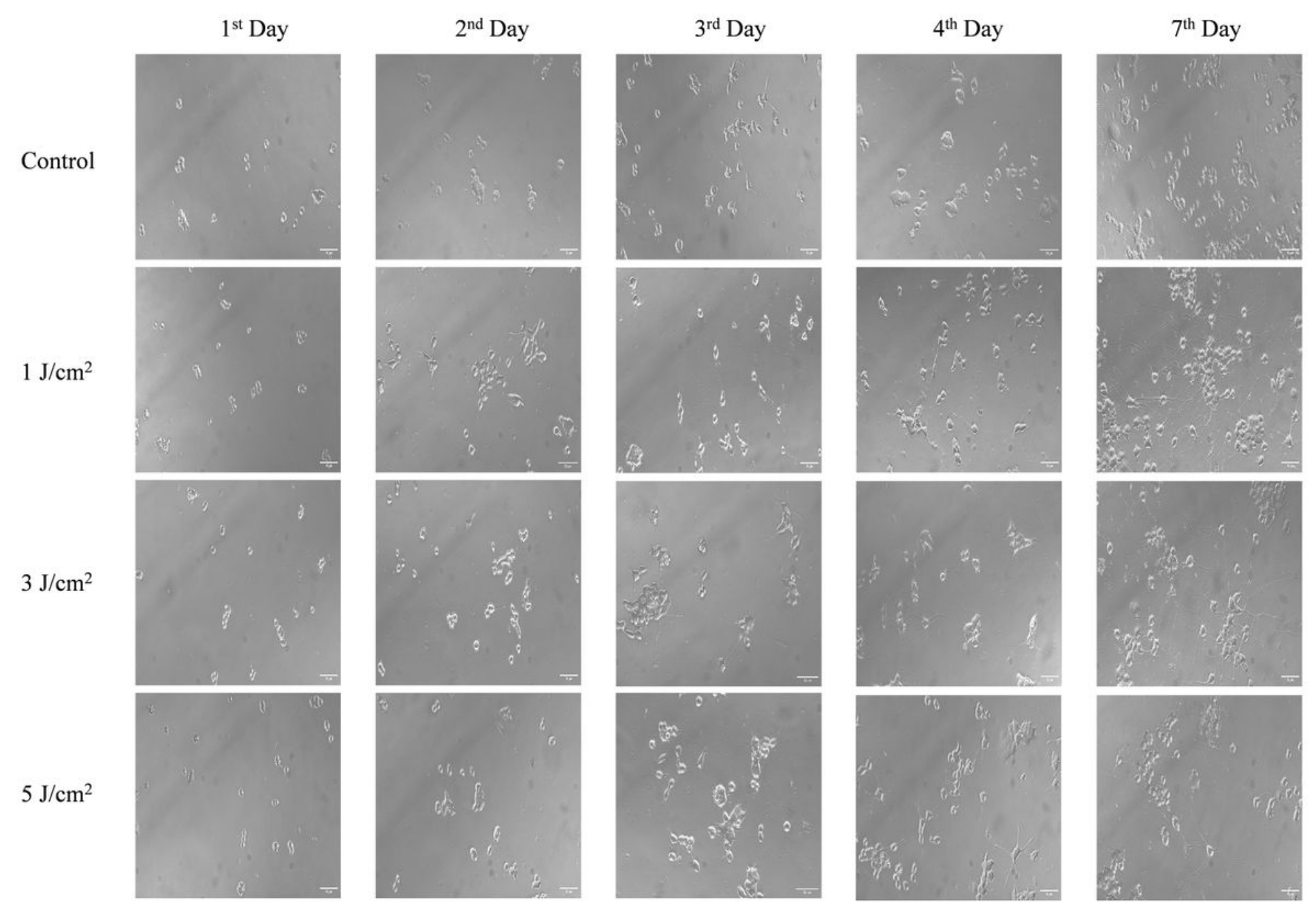

\section{Figure 4}

Microscopic images of PC12 cells in PBM groups obtained on days 1, 2, 3, 4, and 7 (Scale bar: $100 \mu \mathrm{m}$ ). Applied energy densities: 1,3 , and $5 \mathrm{~J} / \mathrm{cm} 2$ 


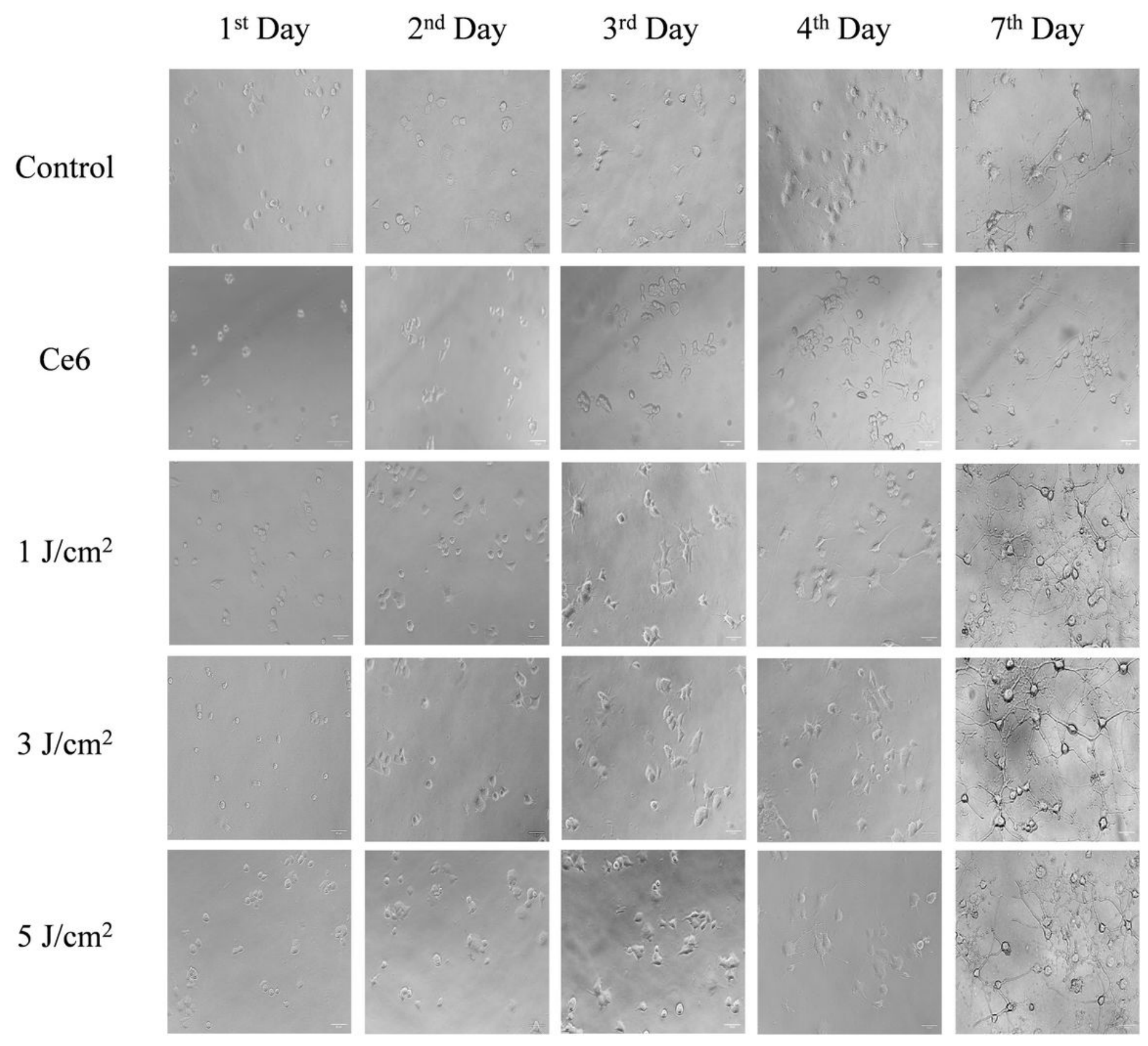

Figure 5

Microscopic images of PC12 cells in low-dose PDT groups obtained on days 1, 2, 3, 4, and 7 (Scale bar: $100 \mu \mathrm{m})$. Applied energy densities: 1, 3, and $5 \mathrm{~J} / \mathrm{cm} 2$ and photosensitizer concentration: $0.1 \mu \mathrm{M}$ 


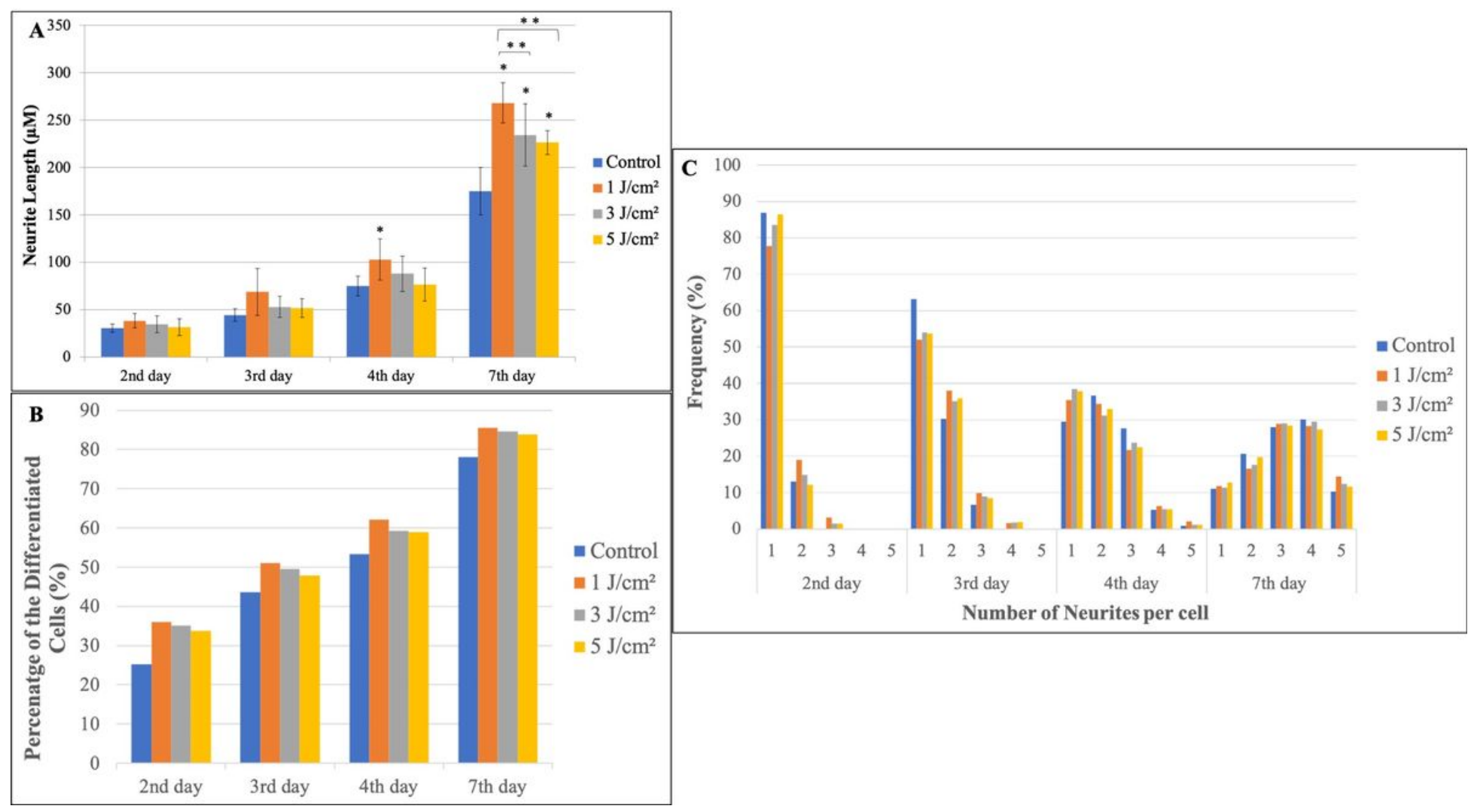

Figure 6

Morphological analysis of PC12 cells in PBM groups. A. Average neurite length measured at days 2, 3, 4, and 7. Each bar represented the average of the neurite length \pm SD. Statistically significant differences were determined by one-way ANOVA followed by Tukey's post hoc test $(p<0.05$, * indicates significant differences compared to the control group and $* \star$ indicates significant differences between the experimental groups), B. Number of neurites per cell counted at day 2, 3, 4, and 7, C. Percentage of the differentiated cells calculated at day 2,3,4, and 7 after PBM applications 


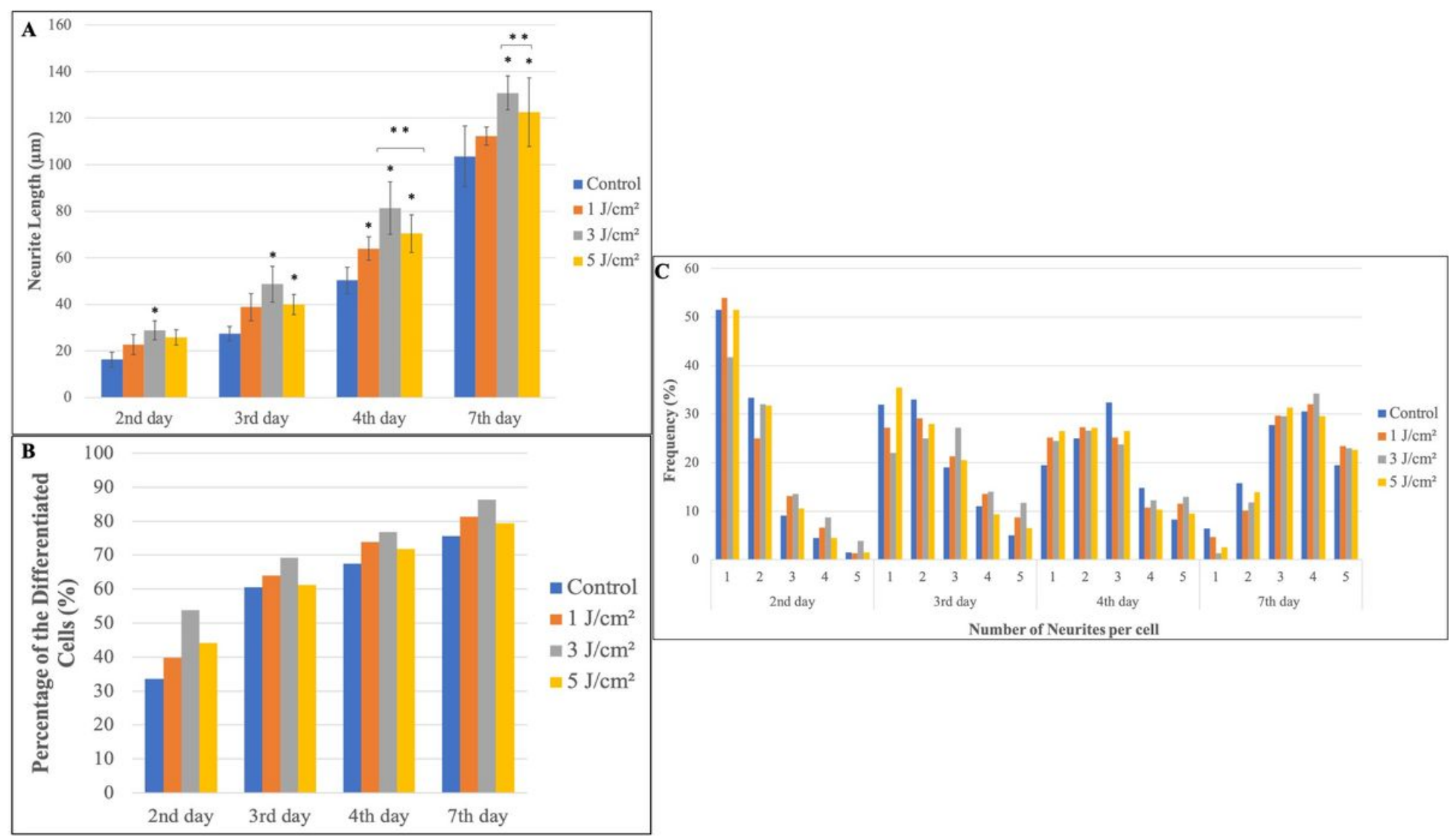

\section{Figure 7}

Morphological analysis of PC12 cells in low-dose PDT groups. A. Average neurite length measured at days $2,3,4$, and 7 . Each bar represented the average of the neurite length \pm SD. Statistically significant differences were determined by one-way ANOVA followed by Tukey's post hoc test $(p<0.05$, * indicates significant differences compared to the control group and ** indicates significant differences between the experimental groups), B. Number of neurites per cell counted at day 2, 3, 4, and 7, C. Percentage of the differentiated cells calculated at day 2, 3, 4, and 7 after low-dose PDT applications. Statistically significant differences were determined by one-way ANOVA followed by Tukey's post hoc test $(p<0.05$, * indicates significant differences compared to the control group and $* *$ indicates significant differences between the experimental groups) 


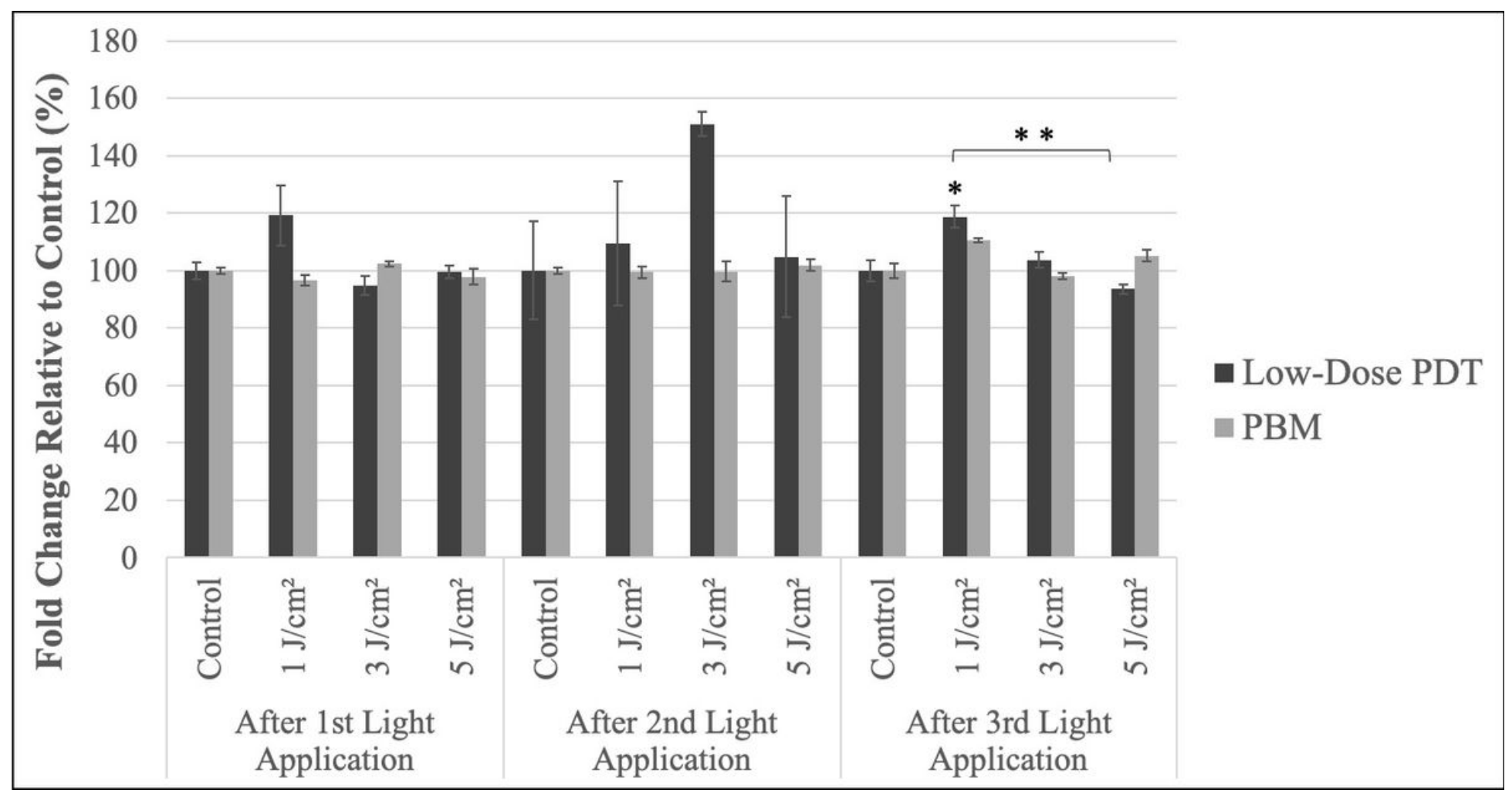

Figure 8

Comparison of the intracellular ROS production in the PBM and Low-Dose PDT groups, which was measured immediately after each light application. Each bar represented the average of the normalized data with respect to the control group \pm SD. Statistically significant differences were determined by oneway ANOVA followed by Tukey's post hoc test $(p<0.05$, * indicates significant differences compared to the control group and $* \star$ indicates significant differences between the experimental groups) 


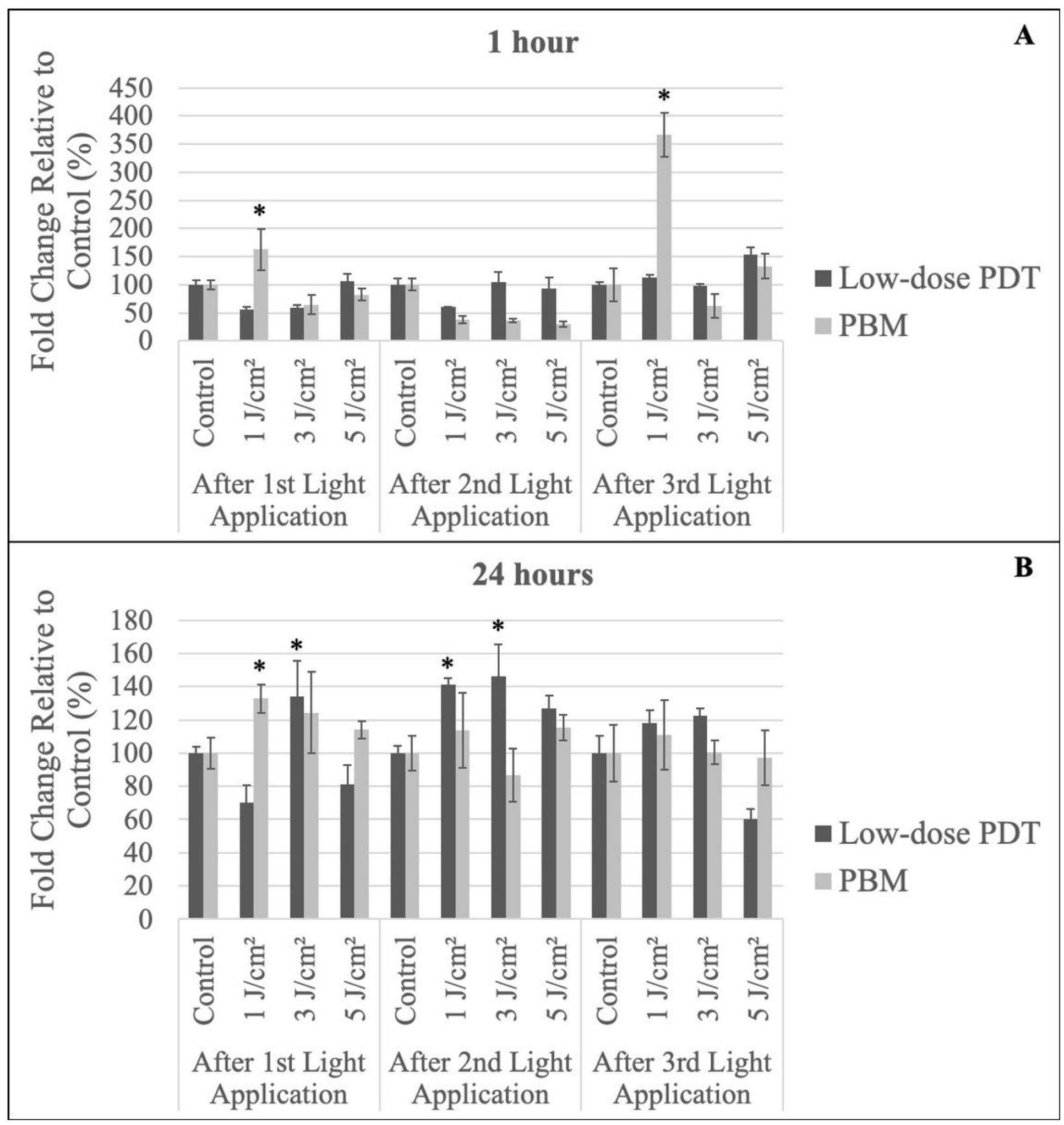

Figure 9

Comparison of the NO release in the PBM and low-dose PDT groups, which was measured A. after 1 hour, B. after 24 hours. Each bar represented the average of the normalized data with respect to the control group \pm SD. Statistically significant differences were determined by one-way ANOVA followed by Tukey's post hoc test $(p<0.05$, * indicates significant differences compared to the control group and ** indicates significant differences between the experimental groups) 


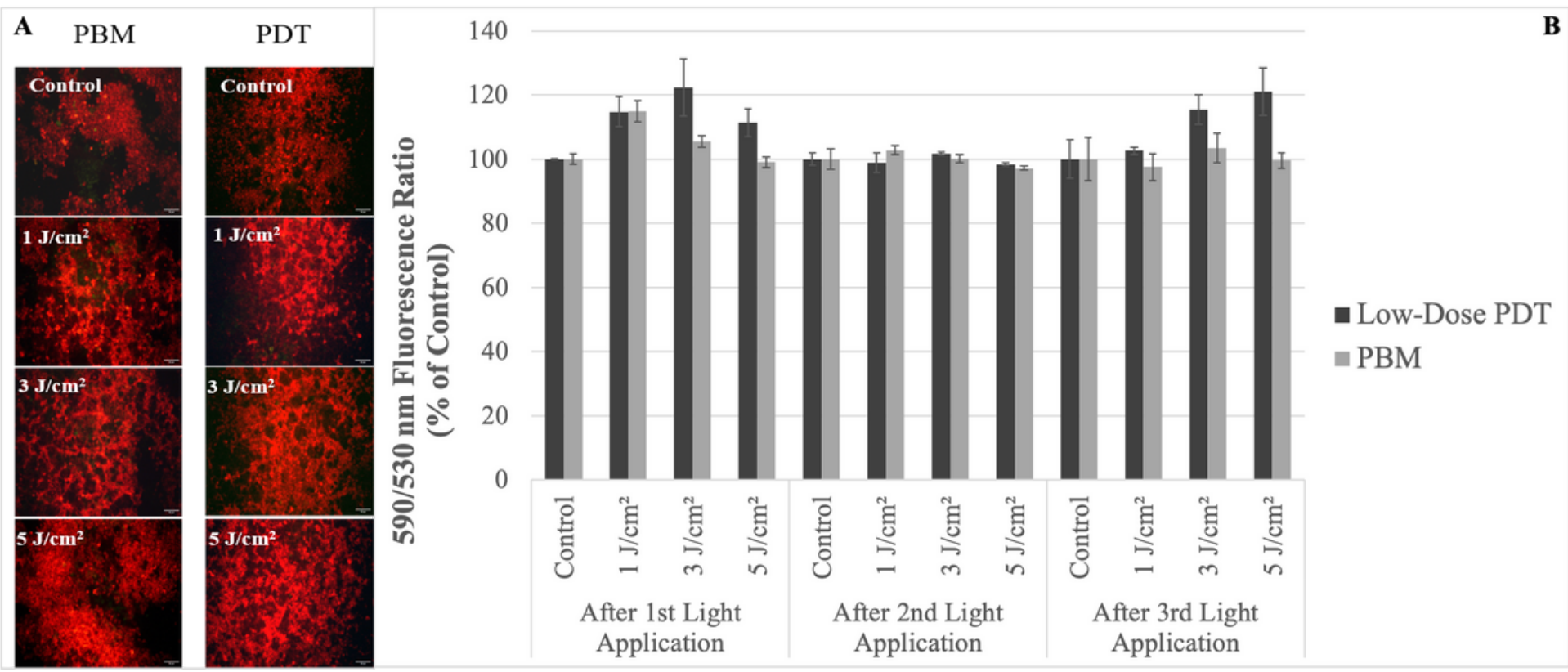

Figure 10

MMP change analysis after PBM and low-dose PDT applications. A. Fluorescent images of PC12 which was incubated with JC-1 probe (scale bar: $100 \mu \mathrm{m}$ ). B. Comparison of the MMP change in the PBM and low-dose PDT groups, which was measured immediately after each light application. Each bar represented the average of the normalized data with respect to the control group \pm SD.

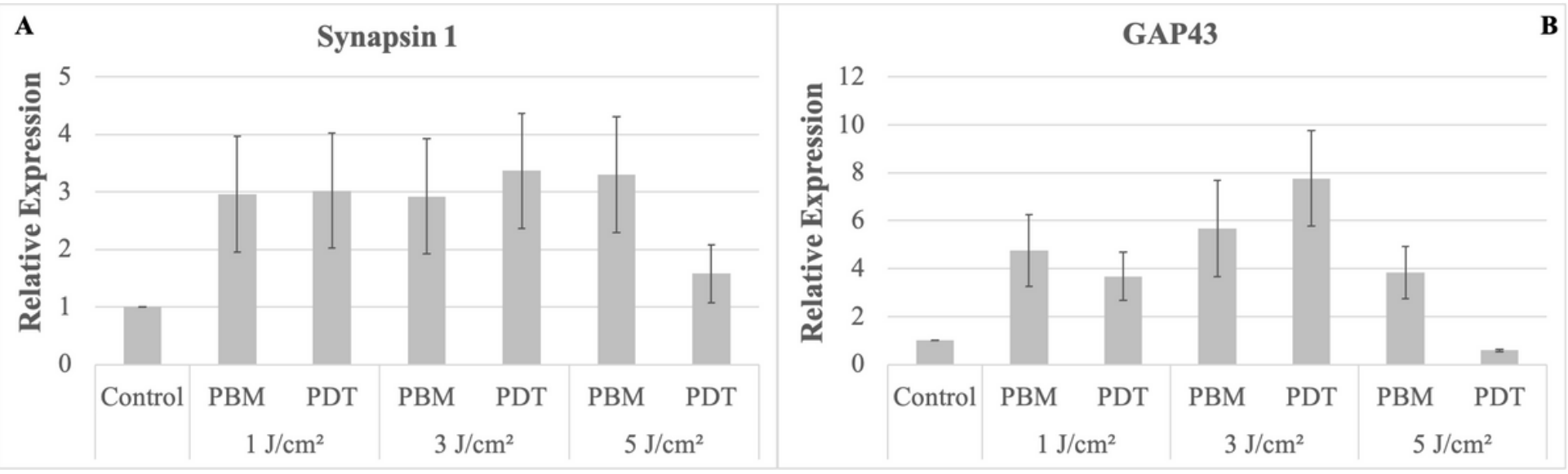

\section{Figure 11}

Comparison of the Synapsin 1 and GAP43 expressions in PBM and low-dose PDT applications. A.

Relative Expression of Synapsin 1, B. Relative Expression of GAP43 in each experimental group. Each bar represented the average of the normalized data with respect to the control group \pm SD.

\section{Supplementary Files}

This is a list of supplementary files associated with this preprint. Click to download. 
- graphicalabstract.png

Page 34/34 